\title{
Knowledge, Attitude, and Practice among Egyptian Travelers: Pre-travel Vaccination and Malaria Prophylaxis
}

\author{
Engy Mohamed El-Ghitany ${ }^{1 *}$, Mohamed Abdelsalam Mohamed Abdelmohsen ${ }^{1}$, Azza Galal Farghaly ${ }^{1}$, Ensaf \\ Saied Abd El-Gawwad'2 Ekram Wassim Abd El-Wahab ${ }^{1}$
}

\author{
${ }^{1}$ Tropical Health Department, High Institute of Public Health, Alexandria University, Alexandria, Egypt \\ ${ }^{2}$ Health Education and Behavioral Science Department, High Institute of Public Health, Alexandria University, \\ Alexandria, Egypt
}

Corresponding Author: Engy Mohamed El-Ghitany, Dr.PH, MPH, DTM\&H, Tropical Health Department, High Institute of Public Health, Alexandria University, 165 El-Horreya Avenue, Alexandria, Egypt. Tel: +2-01001781333, Fax: +2-035457037, Email: ingy.elghitany@gmail.com

Received July 28, 2018; Accepted August 13, 2018; Online Published September 25, 2018

\begin{abstract}
Introduction: More than one third of travelers to developing countries report health problems when traveling. The Egyptian Ministry of Health reports the occurrence of 400 cases of malarial infection yearly among Egyptian travelers. This article aimed to assess the knowledge, attitude, and practice (KAP) of Egyptian travelers towards infectious diseases, vaccination, and malaria chemoprophylaxis. Methods: A survey was conducted at Cairo International Airport and included 1500 travelers. The questionnaire inquired about the travelers' knowledge about infectious diseases at their destinations and their KAP regarding vaccination, malaria, and its prophylaxis. Results: Most travelers (68\%) had poor knowledge, specifically; 90.2\%, 85.6\%, 88.5\% did not know the endemic diseases at their destinations, the modes of disease transmission, or the protective measures against disease, respectively. Knowledge about malaria prevalence, symptoms, modes of transmission, and prevention was good in only $18 \%, 29.8 \%, 6.7 \%$, and $21.4 \%$ of travelers, respectively. Poor practice of malaria prophylactic measures was found in $66.3 \%$ of travelers. Although $91.3 \%$ did not receive any vaccination, the general attitude towards vaccination was good. The total travel health knowledge, practice, general attitude toward vaccination, and the perceived benefits of malarial prophylaxis scores were significantly correlated with older age and high socioeconomic level. Most of the studied travelers $(90.4 \%)$ did not carry or use malaria chemoprophylaxis. Ignorance was the main barrier to receiving vaccines $(65.3 \%)$ and to adherence to malaria chemoprophylaxis (88.3\%).

Conclusion: Egyptian travelers have poor travel health knowledge and practices. Their knowledge and practice scores improve with older age, urban residence, and higher educational levels. They have a good attitude towards vaccination, and ignorance was the main barrier to sound practices.

Keywords: Egypt, Survey, Travel Health, Malaria, Vaccine-Preventable Diseases
\end{abstract}

Citation: El-Ghitany EM, Mohamed Abdelmohsen MA, Farghaly AG, Abd El-Gawwad ES, Abd El- Wahab EW. Knowledge, attitude, and practice among Egyptian travelers: pre-travel vaccination and malaria prophylaxis. Int J Travel Med Glob Health. 2018;6(3):125-136. doi:10.15171/ ijtmgh.2018.23.

\section{Introduction}

The number of people traveling internationally has continued to grow substantially in the past decade. According to the long-term forecast of the United Nations World Tourism Organization(UNWTO) Tourism Towards 2030, international tourist arrivals worldwide are expected to increase by $3.3 \%$ per year between 2014 and 2030 to reach 1.8 billion by $2030 .{ }^{1}$

More than one third of travelers to developing countries report some health problems when traveling. Studies show that $50 \%$ to $75 \%$ of travelers to these regions develop some type of health problem. Most problems are minor; however, about $5 \%$ require medical attention, and less than $1 \%$ require hospitalization. ${ }^{2}$

The US Department of State reports that over 6000 Americans die abroad each year, and the Health Protection Agency Office in the United Kingdom reports that more than 4000 British nationals die abroad annually. ${ }^{3}$

In fact, all major epidemics that have afflicted the human race have been spread internationally by travelers. Furthermore, travelers can contribute to the global spread of

Copyright $(\odot 2018$ The Author(s). This is an open-access article distributed under the terms of the Creative Commons Attribution License (http:// creativecommons.org/licenses/by/4.0), which permits unrestricted use, distribution, and reproduction in any medium, provided the original work is properly cited. 
infectious diseases, including novel and emerging pathogens. Examples are the plague, which killed one third of the affected population throughout Europe between the fourteenth and eighteenth centuries, and syphilis, which is believed to have originally been imported into Europe from the New World by Spanish sailors. ${ }^{4}$

Recent outbreaks of vaccine-preventable diseases such as measles and mumps in the United States have been traced to contact with persons who had traveled to locations where vaccination was less prevalent. ${ }^{5}$ In addition, travel and migration have contributed to the recent introduction or reintroduction of vector-borne diseases in places that had previously been free from these diseases, such as the locally acquired dengue in Florida ${ }^{6}$ and malaria in Greece. ${ }^{7}$

In 2003, a catastrophic event happened during Egypt's participation in the "All African Games 2003 - Abuja-Nigeria". Some Egyptian players were infected with malaria, and two of them died. Despite the official announcement that antimalarial chemoprophylaxis was provided for the players and that it was the players' responsibility to take the drug, this incident denoted a major need for improvement in pretravel malaria prevention strategy. ${ }^{8}$

The Egyptian Ministry of Health announced that about 400 cases of malarial infection occur yearly among Egyptian travelers. ${ }^{9}$ Therefore, to minimize the risk of getting imported infections from incoming and outbound Egyptian travelers and to avoid any potential health problems in the future, travel health facilities must be well established.

To the best of our knowledge, only one study has been done at the El-Fayoum University in 2011 that addressed travel medicine among national and international travelers in Egypt. It concluded that travelers' knowledge of safety measures was lacking, and travel agencies had no obvious role in this regard. ${ }^{10}$

To appropriately improve the provision of travel health, the current status of travelers' knowledge, attitude, and practice (KAP) must be addressed. Therefore, a travel health survey was initiated to learn where people stand regarding all aspects of travel health. In the first part of this survey, risk perception and healthcare-seeking behavior were assessed, and a subjective evaluation of travel health services in Egypt was done. ${ }^{11}$ In this part of the survey, Egyptian travelers' KAP towards infectious diseases, vaccination, and malaria chemoprophylaxis was assessed together to provide a baseline description of Egyptian travelers' KAP towards travel medicine.

\section{Methods}

This cross-sectional study is a continuation of our survey conducted at Cairo International Airport that screened 1500 Egyptian passengers at least 18 years of age traveling to Africa (excluding North Africa), Southeast Asia, or Latin America. ${ }^{11}$ Participants were chosen from among the passengers in the departure halls for the targeted destinations by simple random sampling and on a voluntary basis.

Development of the Questionnaire

A face-to-face interview questionnaire that measures the
KAP of travelers was developed through an Internetbased literature search on worldwide KAP studies, guided by the European Travel Health Advisory Board (ETHAB) standardized questionnaire ${ }^{12}$ and frequent meetings with travel health and behavioral science consultants. The original questionnaire for the survey included 71 questions and was divided into 10 sections. For this part of the study, 3 sections comprising 28 questions were used.

- Knowledge of infectious diseases at destinations and destination requirements for a special health certificate. This was assessed through 3 open-ended questions regarding the prevalence of the most common diseases at the destinations, their modes of transmission, and prevention methods. The travelers were asked about the destination's requirements for a special health or vaccination certification.

- Travelers' KAP towards travels vaccinations; knowledge was assessed by asking about the vaccines required by the traveler's destination. Attitude towards different aspects of vaccination was measured by 9 items measured on a 3-point Likert-like scale, including vaccination efficiency, importance, cost, side effects, safety, and general experience with vaccination. The practice of travelers was investigated through a query about keeping up with recommended medications, prophylactic drugs, protective and safety measures, and receiving required vaccines. Perceived barriers for obtaining vaccinations and the occurrence of any reactions to vaccines were also addressed.

- Travelers' KAP regarding malaria infection; Knowledge and perceptions about the prevalence of malaria at the destination, the signs and symptoms of malaria, modes of infection, and protection methods were assessed using Health Belief Model components, ${ }^{12}$ which include the perceived malaria threat (perceived susceptibility and perceived severity of malarial disease), and the perceived benefits and barriers of malarial prophylaxis for both drugs and protective measures. Questions concerning perceived susceptibility, perceived severity, and perceived benefits were measured on a 3-point Likert-like scale, while perceived barriers were ascertained through openended questions. Travelers were also asked about their practices of getting prophylactic drugs and preparing the protective measures.

A scoring system was established for each of the following

- Knowledge about infectious diseases and malaria at destinations.

- Attitude towards travel vaccinations.

- Perceived threat (perceived susceptibility and severity) of malaria infection.

- Perceived benefits of malarial prophylaxis (drugs and protective measures).

- Perceived barriers to obtaining travel vaccinations and malarial prophylaxis (drugs and protective measures).

- Travel health-related practices.

A Likert-like scale in which a score of 0 was given for wrong or do not know answers and the highest score was given to the best answer was applied. The total 
sums of scores for questions regarding each parameter were grouped into three ranked categories. The lowest was referred to as low, poor, or negative; the middle was referred to as intermediate, fair, or neutral; and the highest was referred to as high, good, or positive.

\section{Pilot Study}

A pilot testing of the questionnaire was carried out from January to October 2014 at Alexandria Fever Hospital. The questionnaire was tested on 50 individuals among those being evaluated for blood-borne viral infections (HCV, HBV, and HIV) as a prerequisite for traveling to gulf countries. Accordingly, the reliability of the questionnaire was assured, and modifications were made to the questionnaire including rephrasing, adding, or removing questions.

\section{Data Collection}

Data collection continued from November 2014 to October 2015. Passengers were selected using the simple random sampling technique. The durations of participant interviews ranged from 35 to 45 minutes; thus, the researcher was able to interview 10-15 travelers daily.

\section{Statistical Analysis}

Data was fed to a computer and analyzed using IBM SPSS software package version 20.0. Categorical data was presented in frequencies. Quantitative data was described using mean/ median and standard deviation. The Kolmogorov-Smirnov test was used to test normality of data. The Mann-Whitney test was used for non-parametric quantitative variables to compare two groups, while the Kruskal-Wallis test was used when more than two groups were compared. Spearman rank correlation coefficient was calculated to correlate between two non-parametric quantitative variables. The significance of the obtained results was judged at the $5 \%$ level.

A scoring system was also established for receiving vaccines, using malaria prophylaxis, and intent to use prophylactic measures. A Likert-like scale was applied where a score of 0 was given for no or malpractice and the highest score was given to the best practice. The total sums of scores for questions regarding each parameter questions were grouped into three ranked categories. The lowest was referred to as poor, the middle was referred to as fair, and the highest was referred to as good.

\section{Results}

Knowledge of common infectious diseases, modes of transmission, and preventive measures are displayed in Table 1 by destination. The majority of travelers $(68 \%)$ had a poor total knowledge level; about one third (31.9\%) had fair knowledge, and only one traveler $(0.1 \%)$ had good knowledge.

In general, most travelers $(90.2 \%)$ had a poor knowledge of the existence of specific diseases in each region. Fair and good knowledge accounted for only $7.9 \%$ and $1.9 \%$ of participants, respectively. Likewise, knowledge of modes of transmission and modes of prevention of such diseases was also poor (85.6\% and $88.5 \%$, respectively); yet it was described as good among a minority $(0.9 \%$ and $0.7 \%$, respectively).
The knowledge and elements of attitude towards vaccination as well as practices and barriers of vaccination are illustrated in Tables 2 and 3.

The knowledge about malaria prevalence at travel destinations was found to be poor among nearly two thirds (63.3\%) of travelers, whereas equal percentages of participants had fair and good knowledge (about 18\% each). On the other hand, knowledge of the symptoms of malaria was fair among $53.9 \%$, good among $29.8 \%$, but poor among $16.3 \%$ of the travelers. Likewise, knowledge about modes of malaria transmission was fair among $70.0 \%$, poor among $23.3 \%$, and good among $6.7 \%$ of the participants. However, the knowledge about modalities of malaria prevention was poor among $42.5 \%$, fair among $36.1 \%$, and good among $21.4 \%$ of the travelers.

Figure 1 shows the distribution of travelers according to level of attitude about travel associated risks and the Health Belief Model perception about malaria.

The practice of using malarial prophylactic measures was poor among $66.3 \%$, fair among $28.5 \%$, and good among $5.2 \%$ of the travelers. The different malaria prevention practices and barriers are illustrated in Table 4 .

The mean travel health-related knowledge and practice scores (Table 5 and Table 6) were significantly higher among travelers 40 years of age and older, urban residents, those with a higher educational level, those with a higher monthly income, and those with health problems or a past medical history. On the other hand, the presence of health insurance did not significantly affect travel-related practices scores. Those with a travel destination of Africa had better knowledge and achieved significantly better travel-related practice scores than travelers to Asia or America.

The mean travel-related practices differed significantly with different travel purposes but was not affected by previous travel experience.

The total scores of travel health knowledge, practice, and general attitude toward vaccination and the perceived benefits of malarial prophylaxis were significantly correlated with older age, high monthly income, and higher educational level. On the other hand, the total scores of the perception of travelassociated risks, the perceived barriers for vaccination, and the perceived barriers to the use of malarial prophylaxis were significantly correlated with younger age $\left(r_{s}=-0.129, P<0.001\right)$, low monthly income $\left(\mathrm{r}_{\mathrm{s}}=-0.196, P<0.001\right)$, and low educational level $\left(r_{s}=-0.138, P<0.001\right)$. The total score of the perception of the threat of malaria had very weak, insignificant correlations with age, income, and educational level (Table 7).

The positive and negative correlations between different studied elements, namely, the travelers' knowledge of travel-associated diseases and malaria, travel health-related practices, perception of travel-associated risks, attitude toward vaccination, perceived threat of malaria, perceived benefits of malaria prophylaxis (drugs and measures), and perceived barriers to vaccination and malaria prophylaxis (drugs and measures) are demonstrated in Table 8 and Figure 2.

\section{Discussion}

Despite the high educational level of the majority of travelers 
Table 1. Distribution of Travelers at Cairo International Airport According to Knowledge About Infectious Diseases at Destinations

\begin{tabular}{|c|c|c|c|c|c|c|}
\hline \multirow{2}{*}{ Infectious Diseases at Destination } & \multicolumn{2}{|c|}{ Do not Know } & \multicolumn{2}{|c|}{ Correct Incomplete Answer } & \multicolumn{2}{|c|}{ Correct Complete Answer } \\
\hline & No. & $\%$ & No. & $\%$ & No. & $\%$ \\
\hline \multicolumn{7}{|c|}{ Africa $(n=919)$} \\
\hline \multicolumn{7}{|l|}{ Common diseases at destination } \\
\hline -Malaria & 515 & 56.0 & & & 404 & 44.0 \\
\hline$-\mathrm{HIV}$ & 779 & 84.8 & & & 140 & 15.2 \\
\hline$-\mathrm{TB}$ & 880 & 95.8 & - & - & 39 & 4.2 \\
\hline -Ebola & 489 & 53.2 & & & 430 & 46.8 \\
\hline -Pneumonia & 918 & 99.9 & & & 1 & 0.1 \\
\hline \multicolumn{7}{|c|}{ Mode of transmission of these common diseases } \\
\hline -Malaria & 214 & 23.3 & 403 & 43.9 & 2 & 0.2 \\
\hline$-\mathrm{HIV}$ & 21 & 2.3 & 868 & 94.5 & 30 & 3.3 \\
\hline$-\mathrm{TB}$ & 201 & 21.9 & 697 & 75.8 & 21 & 2.3 \\
\hline -Ebola & 745 & 81.1 & 174 & 19.0 & 0 & 0.0 \\
\hline \multicolumn{7}{|c|}{ Preventive measures for these common diseases } \\
\hline -Malaria & 361 & 39.3 & 556 & 60.5 & 2 & 0.2 \\
\hline$-\mathrm{HIV}$ & 28 & 3.0 & 862 & 93.8 & 29 & 3.2 \\
\hline$-\mathrm{TB}$ & 308 & 33.5 & 595 & 64.7 & 16 & 1.7 \\
\hline -Ebola & 790 & 86.0 & 129 & 14.0 & 0 & 0.0 \\
\hline -Pneumonia & 316 & 34.4 & 571 & 62.1 & 32 & 3.5 \\
\hline
\end{tabular}

\begin{tabular}{|c|c|c|c|c|c|c|}
\hline \multicolumn{7}{|c|}{ Asia $(n=427)$} \\
\hline \multicolumn{7}{|c|}{ Common diseases at destination } \\
\hline -Avian & 265 & 62.1 & & & 162 & 37.9 \\
\hline -Diarrhea & 388 & 90.9 & - & - & 39 & 9.1 \\
\hline -Malaria & 362 & 84.8 & & & 65 & 15.2 \\
\hline -Meningitis & 389 & 91.1 & & & 38 & 8.9 \\
\hline -Avian & 172 & 40.3 & 253 & 59.3 & 2 & 0.5 \\
\hline$-\mathrm{HIV}$ & 4 & 0.9 & 410 & 96.0 & 13 & 3.0 \\
\hline -Diarrhea & 8 & 1.9 & 409 & 95.8 & 10 & 2.3 \\
\hline -Malaria & 91 & 21.3 & 335 & 78.5 & 1 & 0.2 \\
\hline -Meningitis & 304 & 71.2 & 121 & 28.3 & 2 & 0.5 \\
\hline \multicolumn{7}{|c|}{ Preventive measures for these common diseases } \\
\hline$-\mathrm{HIV}$ & 7 & 1.6 & 407 & 95.3 & 13 & 3.0 \\
\hline -Diarrhea & 13 & 3.0 & 404 & 94.6 & 10 & 2.3 \\
\hline -Malaria & 187 & 43.8 & 239 & 56.0 & 1 & 0.2 \\
\hline -Meningitis & 317 & 74.2 & 108 & 25.3 & 2 & 0.5 \\
\hline
\end{tabular}

\begin{tabular}{|c|c|c|c|c|c|c|}
\hline -Meningitis & 317 & 74.2 & 108 & 25.3 & 2 & 0.5 \\
\hline \multicolumn{7}{|c|}{ America $(n=154)$} \\
\hline \multicolumn{7}{|c|}{ Common diseases at destination } \\
\hline -Chagas disease & 153 & 99.4 & & & 1 & 0.6 \\
\hline -Dengue fever & 154 & 100.0 & & & 0 & 0.0 \\
\hline$-\mathrm{TB}$ & 153 & 99.4 & - & - & 1 & 0.6 \\
\hline -Gonorrhea & 153 & 99.4 & & & 1 & 0.6 \\
\hline \multicolumn{7}{|c|}{ Mode of transmission of these common diseases } \\
\hline -Chagas disease & 154 & 100.0 & 0 & 0.0 & 0 & 0.0 \\
\hline -Dengue fever & 153 & 99.4 & 0 & 0.0 & 1 & 0.6 \\
\hline$-\mathrm{TB}$ & 28 & 18.2 & 126 & 81.8 & 0 & 0.0 \\
\hline -Gonorrhea & 46 & 29.9 & 108 & 70.1 & 0 & 0.0 \\
\hline -HIV & 0 & 0.0 & 154 & 100.0 & 0 & 0.0 \\
\hline \multicolumn{7}{|c|}{ Preventive measures for these common diseases } \\
\hline -Dengue fever & 153 & 99.4 & 1 & 0.6 & 0 & 0.0 \\
\hline$-\mathrm{TB}$ & 45 & 29.2 & 109 & 70.8 & 0 & 0.0 \\
\hline -Gonorrhea & 54 & 35.1 & 100 & 64.9 & 0 & 0.0 \\
\hline$-H I V$ & 0 & 0.0 & 154 & 100.0 & 0 & 0.0 \\
\hline
\end{tabular}


Table 2. Distribution of Travelers at Cairo International Airport According to Knowledge and Attitude Towards Vaccination

\begin{tabular}{|c|c|c|}
\hline Knowledge and Attitude Towards Vaccination $(n=1500)$ & No. & $\%$ \\
\hline \multicolumn{3}{|l|}{ Vaccines required for the destination country } \\
\hline -Do not know-wrong answer & 1020 & 68.0 \\
\hline -Correct incomplete answer & 479 & 31.9 \\
\hline -Correct complete answer & 1 & 0.1 \\
\hline \multicolumn{3}{|l|}{ Attitude towards vaccination protection } \\
\hline -Does not provide protection & 19 & 1.3 \\
\hline -Medium protection & 303 & 20.2 \\
\hline -Maximum protection & 1178 & 78.5 \\
\hline \multicolumn{3}{|l|}{ Necessity } \\
\hline -Unnecessary & 30 & 2.0 \\
\hline -May be necessary & 910 & 60.7 \\
\hline -Totally necessary & 560 & 37.3 \\
\hline \multicolumn{3}{|l|}{ Cost } \\
\hline -Expensive & 382 & 25.5 \\
\hline -Medium cost & 992 & 66.1 \\
\hline -Cheap & 126 & 8.4 \\
\hline \multicolumn{3}{|l|}{ Side effects } \\
\hline$-A$ lot & 249 & 16.6 \\
\hline -Some & 1063 & 70.9 \\
\hline -Rare & 188 & 12.5 \\
\hline \multicolumn{3}{|l|}{ Safety } \\
\hline -Harmful & 58 & 3.9 \\
\hline -Some harm & 1225 & 81.7 \\
\hline -Completely safe & 217 & 14.5 \\
\hline \multicolumn{3}{|l|}{ Pain } \\
\hline -Very painful & 305 & 20.3 \\
\hline -Painful & 1077 & 71.8 \\
\hline -Does not cause pain & 118 & 7.9 \\
\hline \multicolumn{3}{|l|}{ General attitude towards vaccination } \\
\hline -Negative & 33 & 2.2 \\
\hline -Neutral & 459 & 30.6 \\
\hline -Positive & 1008 & 67.2 \\
\hline \multicolumn{3}{|l|}{ Informal ways to get vaccination certificate } \\
\hline -Agree & 181 & 12.1 \\
\hline -Neutral & 364 & 24.3 \\
\hline -Disagree & 955 & 63.7 \\
\hline
\end{tabular}

in this study, the overall knowledge and practice was poor. A high level of knowledge was reported in $83.7 \%$ of French travelers $^{14}$ and $55 \%$ of travelers from Chile. ${ }^{15}$ In the same context, $68 \%$ of travelers did not know the exact vaccination required for their destinations, compared to Spanish (55.2\%), ${ }^{16}$ Australian (32\%), ${ }^{17}$ and American (36\%) travelers. ${ }^{18}$

Only $8.6 \%$ of travelers received vaccinations prior to travel, and those were mainly yellow fever (8.6\%) and meningococcal (1.3\%) vaccines which were received as a requirement of the destination. However, in a Spanish survey, about half of the respondents received pre-travel vaccinations. ${ }^{16}$

Usually travelers to the tropics receive a more extended list of vaccines. In the United States ${ }^{18}$ [tetanus (11\%), HAV (14\%), HBV (13\%), and yellow fever (5\%)]; in southern Africa $^{19}$ [yellow fever (41\%), tetanus (22\%), HAV (23\%), and meningitis (17\%)]; in Chile ${ }^{15}$ [typhoid (32\%), yellow fever
Table 3. Distribution of Travelers at Cairo International Airport According to Practices and Barriers of Vaccination

\begin{tabular}{|c|c|c|}
\hline Practices and Barriers of Vaccination $(n=1500)$ & No. & $\%$ \\
\hline \multicolumn{3}{|l|}{ Receiving vaccines required by destination * } \\
\hline$-\mathrm{No}$ & 1370 & 91.3 \\
\hline$-\mathrm{HAV}$ & 5 & 0.3 \\
\hline -Tetanus & 1 & 0.1 \\
\hline -Cholera & 2 & 0.1 \\
\hline -Influenza & 4 & 0.3 \\
\hline -Meningococcal & 19 & 1.3 \\
\hline -Yellow fever & 129 & 8.6 \\
\hline \multicolumn{3}{|c|}{ Perceived barriers for not receiving vaccinations $(n=1370)^{*}$} \\
\hline -Short length of stay & 325 & 23.7 \\
\hline -I am not exposed to diseases & 1 & 0.1 \\
\hline -I do not know the existing diseases & 199 & 14.5 \\
\hline -These diseases were not dangerous & 3 & 0.2 \\
\hline -I was previously vaccinated & 138 & 10.1 \\
\hline -I do not know that I should get the vaccine & 1154 & 84.2 \\
\hline -I dislike vaccination & 34 & 2.5 \\
\hline -Others** & 7 & 0.5 \\
\hline \multicolumn{3}{|l|}{ Occurrence of any vaccination reactions $(n=130)^{*}$} \\
\hline$-\mathrm{No}$ & 78 & 60.0 \\
\hline -Pain & 15 & 11.5 \\
\hline -Fever & 40 & 30.8 \\
\hline -Headache & 4 & 3.1 \\
\hline -Skin rash & 2 & 1.5 \\
\hline
\end{tabular}

* Multiple response question.

** Others = Receiving vaccination at destination; depending on God; nobody was vaccinated before; these diseases were not common at destination; no history of getting infected in previous visit; or it is not necessary to get the vaccines.

(29\%), tetanus (24\%), and HAV (14\%)]; in Europe ${ }^{20}$ [tetanus (51\%), HAV (37\%), typhoid fever (25\%), and HBV (2\%)]; and in Australia ${ }^{17}$ [HAV (5\%), HBV (5\%), yellow fever (2\%), and meningitis (25\%)] are the required vaccinations. The main perceived barrier to obtaining vaccinations was ignorance of the need for vaccinations $(84.2 \%)$.

Despite the travelers' poor knowledge and practice of obtaining travel vaccinations, the general attitude towards vaccination was good (high among 55\% and medium among $37 \%$ of the participants). More than three quarters (78.5\%) of the respondents considered vaccinations to be highly protective compared to $50.7 \%$ of Japanese travelers, ${ }^{21} 83.4 \%$ of European travelers, ${ }^{20}$ and $69.1 \%$ of Chinese travelers. ${ }^{22}$ This is a promising finding that urges intervention to improve knowledge and services with expected great improvement in vaccine usage.

Knowledge of the prevalence of malaria at destinations was deficient among Egyptian travelers; 63.3\% did not know the prevalence of malaria in their destination. This was in accordance with reports among Chinese travelers, where $82 \%$ did not know the exact malaria risk at their destinations. ${ }^{23}$

More than three fourths of Egyptian travelers made a correct association between malaria and mosquitos as a mode of disease transmission. These are encouraging results and similar to those in Switzerland ${ }^{24}$ and Portugal ${ }^{25}$ where $95 \%$ 


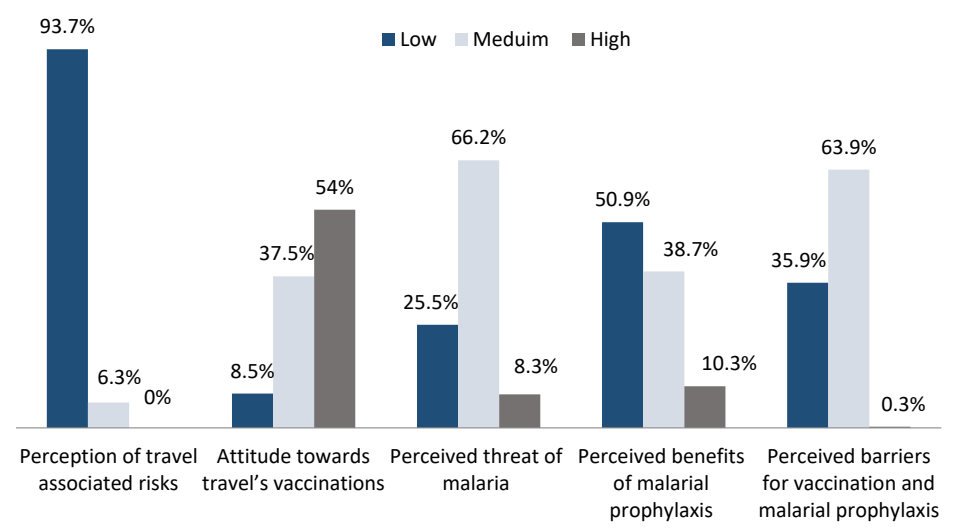

Figure 1. Distribution of Travelers at Cairo International Airport According to Level of Attitude About Travel-Associated Risks and Health Belief Model Perception About Malaria.

Table 4. Distribution of Travelers at Cairo International Airport Regarding Practices and Barriers of Malarial Prophylaxis (Drugs and Measures)

\begin{tabular}{|c|c|c|}
\hline Practices and Barriers to Use of Malarial Prophylaxis (Drugs and Measures) $(n=1500)$ & No. & $\%$ \\
\hline \multicolumn{3}{|l|}{ Carrying or using malaria chemoprophylaxis } \\
\hline$-\mathrm{No}$ & 1356 & 90.4 \\
\hline -Yes, use it as prophylaxis & 141 & 9.4 \\
\hline -Yes, use it in case of being infected & 3 & 0.2 \\
\hline \multicolumn{3}{|l|}{ What is the drug? } \\
\hline -Lariam & 144 & 100.0 \\
\hline \multicolumn{3}{|l|}{ Perceived barriers of taking malaria chemoprophylaxis $(n=1356)^{*}$} \\
\hline -I do not know these drugs & 1198 & 88.3 \\
\hline -Nobody prescribed them to me & 13 & 1.0 \\
\hline -It is not necessary & 106 & 7.8 \\
\hline -Trust in God & 504 & 37.2 \\
\hline -Others** & 33 & 2.4 \\
\hline \multicolumn{3}{|l|}{ Duration of malaria chemoprophylaxis $(n=144)$} \\
\hline -Before, during, and after travel return & 97 & 67.4 \\
\hline -Before and during travel & 37 & 25.7 \\
\hline -Others $* * *$ & 10 & 6.9 \\
\hline \multicolumn{3}{|l|}{ Occurrence of any health problem on taking malaria chemoprophylaxis $(n=141)$} \\
\hline- No & 141 & 100.0 \\
\hline \multicolumn{3}{|l|}{ Feasibility of obtaining malaria chemoprophylaxis $(n=144)$} \\
\hline$-\mathrm{No}$ & 110 & 76.4 \\
\hline- Yes & 34 & 23.6 \\
\hline \multicolumn{3}{|l|}{ Perception of the possibility of malarial treatment at destination $(n=1500)$} \\
\hline$-\mathrm{No}$ & 111 & 7.4 \\
\hline- Yes & 834 & 55.6 \\
\hline -Do not know & 555 & 37.0 \\
\hline \multicolumn{3}{|l|}{ Prophylactic measures planned to be followed $(n=1500)^{*}$} \\
\hline -Long-sleeved clothing & 234 & 15.6 \\
\hline -Closing doors and windows & 148 & 9.9 \\
\hline -Mosquito repellents & 22 & 1.5 \\
\hline -Insecticides & 423 & 28.2 \\
\hline -Mosquito coils & 29 & 1.9 \\
\hline -Mosquito nets & 25 & 1.7 \\
\hline II will not use any measures & 994 & 66.3 \\
\hline \multicolumn{3}{|l|}{ Perceived barriers for adherence to protective measures $(n=994)^{*}$} \\
\hline$-I$ do not know these measures & 649 & 65.3 \\
\hline -Un-usefulness of these measures & 34 & 3.4 \\
\hline -Some are disgusting, such as creams & 8 & 0.8 \\
\hline -Weather & 2 & 0.2 \\
\hline -Cost & 2 & 0.2 \\
\hline -Daily use is exhausting & 61 & 6.1 \\
\hline -Forgetfulness & 98 & 9.9 \\
\hline -Laziness & 94 & 9.5 \\
\hline -Trust in God & 529 & 53.2 \\
\hline -Others ${ }^{* * * *}$ & 29 & 2.9 \\
\hline
\end{tabular}

* Multiple response question; ** Others = Short duration of stay; will obtain them at destination; I had not seen anybody use them in my previous visits; I will use other methods; ${ }^{* * *}$ Others $=$ Before travel only; during travel only; during and after travel; before and after travel; $* * * *$ Others $=\mathrm{I}$ had not seen anybody used them in my previous visits; I will use the prophylactic drugs; I will stay for a short time; low prevalence of malaria at destination. 
Table 5. Travelers' Total Knowledge Score by Some Sociodemographic and Travel Characteristics

\begin{tabular}{|c|c|c|c|c|c|c|}
\hline \multirow{2}{*}{ Sociodemographic and Travel Characteristics } & \multicolumn{4}{|c|}{ Total Knowledge Score*** } & \multirow{2}{*}{ Test of sig. } & \multirow{2}{*}{$P$} \\
\hline & No. & Mean & $\pm \mathrm{SD}$ & Median & & \\
\hline \multicolumn{7}{|l|}{ Gender } \\
\hline -Male & 1340 & 12.07 & 6.1 & 12.0 & \multirow[t]{2}{*}{$z=0.139$} & \multirow[t]{2}{*}{0.889} \\
\hline -Female & 160 & 11.84 & 5.1 & 12.5 & & \\
\hline \multicolumn{7}{|l|}{ Age in years } \\
\hline$-<30$ & 538 & 9.48 & 5.06 & 9.0 & \multirow{3}{*}{${ }^{\mathrm{kW}} \mathrm{X}^{2}=172.92^{*}$} & \multirow{3}{*}{$<0.001^{*}$} \\
\hline-30 to $<40$ & 691 & 13.11 & 6.04 & 13.0 & & \\
\hline$-40+$ & 271 & 14.42 & 5.68 & 15.0 & & \\
\hline \multicolumn{7}{|l|}{ Residency } \\
\hline -Rural & 163 & 10.08 & 5.57 & 10.0 & \multirow{2}{*}{$z=4.15^{*}$} & \multirow{2}{*}{$<0.001^{*}$} \\
\hline -Urban & 1337 & 12.28 & 5.98 & 12.0 & & \\
\hline \multicolumn{7}{|l|}{ Marital status } \\
\hline -Unmarried & 512 & 9.41 & 5.19 & 9.0 & \multirow{2}{*}{$z=12.75^{*}$} & \multirow{2}{*}{$<0.001^{*}$} \\
\hline -Married & 988 & 13.41 & 5.89 & 13.0 & & \\
\hline \multicolumn{7}{|l|}{ Education level } \\
\hline -Illiterate & 9 & 5.33 & 4.03 & 4.0 & \multirow{4}{*}{${ }^{\mathrm{KW}} \mathrm{x}^{2}=226.98^{*}$} & \multirow{4}{*}{$<0.001^{*}$} \\
\hline -Less than 9 years education & 81 & 5.54 & 3.79 & 4.0 & & \\
\hline -Secondary & 160 & 8.06 & 4.79 & 7.0 & & \\
\hline -University and post-graduate education & 1250 & 13.03 & 5.72 & 13.0 & & \\
\hline \multicolumn{7}{|l|}{ Education type } \\
\hline -Literature & 419 & 12.05 & 4.92 & 12.0 & \multirow{3}{*}{${ }^{k W} x^{2}=236.16^{*}$} & \multirow{3}{*}{$<0.001^{*}$} \\
\hline -Scientific & 867 & 11.31 & 4.96 & 11.0 & & \\
\hline -Medical & 124 & 22.01 & 5.69 & 21.5 & & \\
\hline Monthly income & & & & & & \\
\hline -Not enough & 416 & 9.18 & 5.45 & 9.0 & & \\
\hline -Enough & 1073 & 13.13 & 5.80 & 13.0 & ${ }^{\mathrm{kW}} \mathrm{x}^{2}=144.76^{*}$ & $<0.001^{*}$ \\
\hline -Enough and saving & 11 & 14.73 & 5.66 & 16.0 & & \\
\hline Medical history & & & & & & \\
\hline$-\mathrm{No}$ & 1178 & 11.66 & 6.0 & 11.0 & $7=5.32^{*}$ & $<0001^{*}$ \\
\hline -Yes & 322 & 13.45 & 5.66 & 13.0 & & \\
\hline Previous travels & & & & & & \\
\hline$-\mathrm{No}$ & 842 & 10.62 & 5.87 & 10.0 & $18:$ & $<0 \Omega 01^{*}$ \\
\hline- Yes & 658 & 13.87 & 5.59 & 14.0 & $2-11.00$ & -0.001 \\
\hline Destination & & & & & & \\
\hline -Africa & 919 & 12.76 & 6.42 & 13.0 & & \\
\hline -Asia & 427 & 12.0 & 5.17 & 12.0 & ${ }^{\mathrm{kW}} \mathrm{x}^{2}=107.99^{*}$ & $<0.001^{*}$ \\
\hline -America & 154 & 7.84 & 2.53 & 8.0 & & \\
\hline Purpose of travel & & & & & & \\
\hline -Tourism & 176 & 10.56 & 4.93 & 10.0 & & \\
\hline -Work & 1037 & 12.21 & 6.16 & 12.0 & & \\
\hline -Study & 3 & 19.33 & 1.15 & 20.0 & $\mathrm{KW}^{2}{ }^{2}=21.81^{*}$ & $0.001^{*}$ \\
\hline -Seeking medical treatment & 4 & 8.75 & 2.99 & 9.0 & & \\
\hline -Sports & 140 & 11.81 & 5.67 & 11.5 & & \\
\hline -Others** & 140 & 12.86 & 5.78 & 13.0 & & \\
\hline Presence of health insurance & & & & & & \\
\hline$-\mathrm{No}$ & 1152 & 11.53 & 5.94 & 11.0 & $z=6.52^{*}$ & $<0.001^{*}$ \\
\hline -Yes & 348 & 13.73 & 5.75 & 13.0 & & 20.001 \\
\hline
\end{tabular}

KW: Kruskal Wallis test for comparing between the different studied group; z: z value for Mann Whitney test.

*Statistically significant; ** Others = Parents or husband accompanying; visiting relatives; attending conference; making a movie; Quran memorization competition; relief committee; traditional arts competition; ***Knowledge total score range (0-40). 
Table 6. Total Travel-Related Practices Score Among Studied Travelers by Some Sociodemographic and Travel Characteristics

\begin{tabular}{|c|c|c|c|c|c|c|}
\hline \multirow{2}{*}{ Sociodemographic and Travel Characteristics } & \multicolumn{4}{|c|}{ Total Travel-Related Practices Score*** } & \multirow{2}{*}{ Test of sig. } & \multirow{2}{*}{$P$} \\
\hline & No. & Mean & $\pm \mathrm{SD}$ & Median & & \\
\hline \multicolumn{7}{|l|}{ Gender } \\
\hline -Male & 1340 & 2.89 & 4.2 & 2.0 & \multirow[t]{2}{*}{$z=2.729^{*}$} & \multirow[t]{2}{*}{$0.006^{*}$} \\
\hline -Female & 160 & 2.92 & 3.2 & 2.0 & & \\
\hline \multicolumn{7}{|l|}{ Age (y) } \\
\hline$-<30$ & 538 & 2.05 & 3.14 & 2.0 & \multirow{3}{*}{${ }^{\mathrm{kW}} \chi^{2}=36.57^{*}$} & \multirow{3}{*}{$<0.001^{*}$} \\
\hline-30 to $<40$ & 691 & 3.24 & 4.41 & 2.0 & & \\
\hline$-40+$ & 271 & 3.68 & 4.61 & 2.0 & & \\
\hline \multicolumn{7}{|l|}{ Residency } \\
\hline -Rural & 163 & 2.21 & 3.90 & 1.0 & \multirow{2}{*}{$z=4.81^{*}$} & \multirow{2}{*}{$<0.001^{*}$} \\
\hline -Urban & 1337 & 2.97 & 4.11 & 2.0 & & \\
\hline \multicolumn{7}{|l|}{ Marital status } \\
\hline -Unmarried & 512 & 2.01 & 3.07 & 1.0 & \multirow{2}{*}{$z=6.15^{*}$} & \multirow{2}{*}{$<0.001^{*}$} \\
\hline -Married & 988 & 3.35 & 4.46 & 2.0 & & \\
\hline \multicolumn{7}{|l|}{ Education level } \\
\hline -Illiterate & 9 & 0.22 & 0.44 & 0.00 & \multirow{4}{*}{${ }^{\mathrm{kW}} \chi 2=36.57^{*}$} & \multirow{4}{*}{$<0.001^{*}$} \\
\hline -Less than 9 years education & 81 & 0.53 & 1.65 & 0.00 & & \\
\hline -Secondary & 160 & 0.92 & 2.0 & 0.00 & & \\
\hline -University and post-graduate education & 1250 & 3.32 & 4.28 & 2.0 & & \\
\hline \multicolumn{7}{|l|}{ Education type } \\
\hline -Literature & 419 & 2.81 & 3.50 & 2.0 & \multirow{3}{*}{${ }^{\mathrm{kW}} \chi^{2}=195.28^{*}$} & \multirow{3}{*}{$<0.001^{*}$} \\
\hline -Scientific & 867 & 2.41 & 3.40 & 2.0 & & \\
\hline -Medical & 124 & 8.25 & 6.64 & 7.0 & & \\
\hline Monthly income & & & & & & \\
\hline -Not enough & 416 & 1.88 & 3.42 & 1.0 & & \\
\hline -Enough & 1073 & 3.25 & 4.24 & 2.0 & ${ }^{k w} \chi^{2}=109.66^{*}$ & $<0.001^{*}$ \\
\hline -Enough and saving & 11 & 6.36 & 5.35 & 8.0 & & \\
\hline Medical history & & & & & & \\
\hline$-\mathrm{No}$ & 322 & 3.43 & 4.19 & 2.0 & $z=379 *$ & $<0,001 *$ \\
\hline -Yes & 1178 & 2.74 & 4.05 & 2.0 & $z=3.19$ & $<0.001$ \\
\hline Previous travels & & & & & & \\
\hline$-\mathrm{No}$ & 842 & 2.99 & 4.31 & 2.0 & $7-043$ & -06699 \\
\hline -Yes & 658 & 2.77 & 3.78 & 2.0 & $2-0.45$ & $<0.009$ \\
\hline Destination & & & & & & \\
\hline -Africa & 919 & 3.55 & 4.91 & 2.0 & & \\
\hline -Asia & 427 & 1.87 & 1.94 & 2.0 & ${ }^{k W} \chi^{2}=7.44^{*}$ & $<0.024^{*}$ \\
\hline -America & 154 & 1.80 & 1.51 & 2.0 & & \\
\hline Purpose of travel & & & & & & \\
\hline -Tourism & 176 & 2.70 & 2.54 & 2.0 & & \\
\hline -Work & 1037 & 2.79 & 4.30 & 1.0 & & \\
\hline -Study & 3 & 2.67 & 0.58 & 3.0 & $k w_{\chi} 2=47.47^{*}$ & $<0.001^{*}$ \\
\hline -Seeking medical treatment & 4 & 2.0 & 0.82 & 2.0 & $\lambda^{2}-7.11$ & \\
\hline -Sports & 140 & 2.68 & 2.48 & 2.0 & & \\
\hline -Others** & 140 & 4.14 & 5.13 & 2.0 & & \\
\hline Presence of health insurance & & & & & & \\
\hline$-\mathrm{No}$ & 1152 & 2.71 & 3.89 & 2.0 & & $<0.127$ \\
\hline -Yes & 348 & 3.49 & 4.64 & 2.0 & $\angle=1.327$ & -0.121 \\
\hline
\end{tabular}

KW: Kruskal Wallis test for comparing between the different studied group; z: z value for Mann Whitney test.

*Statistically significant; ** Others = Parents or husband accompanying; visiting relatives; attending conference; making a movie; Quran memorization competition; relief committee; traditional arts competition; ***Travel related practices total score range $(0-26)$. 
Table 7. Correlation Between Age, Income, and Education Level With Total Score of Knowledge, Attitude, and Practices

\begin{tabular}{|c|c|c|c|c|}
\hline Knowledge, Practices, and Perception Total Score & & Age (y) & Monthly Income & Education \\
\hline \multirow{2}{*}{ Knowledge total score } & $r_{s}$ & $0.347^{*}$ & $0.311^{*}$ & $0.386^{*}$ \\
\hline & $P$ & $<0.001^{*}$ & $<0.001^{*}$ & $<0.001^{*}$ \\
\hline \multirow{2}{*}{ Travel-related practices total score } & $r_{s}$ & $0.143^{*}$ & $0.233^{*}$ & $0.361^{*}$ \\
\hline & $P$ & $<0.001^{*}$ & $<0.001^{*}$ & $<0.001^{*}$ \\
\hline \multirow{2}{*}{ Perception of travel-associated risks total score } & $r_{s}$ & $-0.129^{*}$ & $-0.196^{*}$ & $-0.138^{*}$ \\
\hline & $P$ & $<0.001^{*}$ & $<0.001^{*}$ & $<0.001^{*}$ \\
\hline Attitude toward vaccination total score & $P$ & $<0.001^{*}$ & $<0.001^{*}$ & $<0.001^{*}$ \\
\hline \multirow{2}{*}{ Perceived threat of malaria total score } & $r_{s}$ & 0.031 & 0.027 & 0.045 \\
\hline & $P$ & 0.226 & 0.291 & 0.083 \\
\hline \multirow{2}{*}{ Perceived benefits of malarial prophylaxis (drugs and measures) total score } & $r_{s}$ & $0.168^{*}$ & $0.162^{*}$ & $0.134^{*}$ \\
\hline & $P$ & $<0.001^{*}$ & $<0.001^{*}$ & $<0.001^{*}$ \\
\hline Perceived barriers of vaccination and malarial prophylaxis (drugs and measures) total score & $r_{s}$ & $-0.222^{*}$ & $-0.180^{*}$ & $-0.210^{*}$ \\
\hline
\end{tabular}

$r_{s}:$ Spearman coefficient.

* Statistically significant.

Table 8. Correlation Matrix Between Scores of Different Elements of KAP and Each Other Among the Studied Group

\begin{tabular}{|c|c|c|c|c|c|c|c|}
\hline \multirow{2}{*}{ Variables } & Knowledge $^{(1)}$ & Practices $^{(2)}$ & Risk-Perception $^{(3)}$ & $\begin{array}{l}\text { Attitude- } \\
\text { Vaccination }^{(4)}\end{array}$ & $\begin{array}{l}\text { Perceived } \\
\text { Threat }^{(5)}\end{array}$ & $\begin{array}{l}\text { Perceived } \\
\text { Benefits }^{(6)}\end{array}$ & $\begin{array}{l}\text { Perceived } \\
\text { Barriers }^{(7)}\end{array}$ \\
\hline & $\begin{array}{l}r \\
P \text { Value } \\
\end{array}$ & $\begin{array}{l}r \\
P \text { Value }\end{array}$ & $\begin{array}{l}r \\
P \text { Value }\end{array}$ & $\begin{array}{l}r \\
P \text { Value }\end{array}$ & $\begin{array}{l}r \\
P \text { Value }\end{array}$ & $\begin{array}{l}r \\
P \text { Value } \\
\end{array}$ & $\begin{array}{l}r \\
P \text { Value }\end{array}$ \\
\hline Knowledge $^{(1)}$ & 1 & & & & & & \\
\hline Practices $^{(2)}$ & $\begin{array}{l}0.534 \\
0.0001^{*}\end{array}$ & 1 & & & & & \\
\hline Risk-perception $^{(3)}$ & $\begin{array}{l}-0.029 \\
0.26\end{array}$ & $\begin{array}{l}0.303 \\
0.0001^{*}\end{array}$ & 1 & & & & \\
\hline Attitude-vaccination ${ }^{(4)}$ & $\begin{array}{l}0.328 \\
0.0001^{*}\end{array}$ & $\begin{array}{l}0.195 \\
0.0001 *\end{array}$ & $\begin{array}{l}-0.081 \\
0.0016^{*}\end{array}$ & 1 & & & \\
\hline Perceived threat ${ }^{(5)}$ & $\begin{array}{l}0.187 \\
0.0001^{*}\end{array}$ & $\begin{array}{l}0.249 \\
0.0001 *\end{array}$ & $\begin{array}{l}0.258 \\
0.0001^{*}\end{array}$ & $\begin{array}{l}0.136 \\
0.0001^{*}\end{array}$ & 1 & & \\
\hline Perceived benefits ${ }^{(6)}$ & $\begin{array}{l}0.557 \\
0.0001^{*}\end{array}$ & $\begin{array}{l}0.374 \\
0.0001^{*}\end{array}$ & $\begin{array}{l}0.019 \\
0.469\end{array}$ & $\begin{array}{l}0.197 \\
0.0001 *\end{array}$ & $\begin{array}{l}0.158 \\
0.0001^{*}\end{array}$ & 1 & \\
\hline Perceived barriers ${ }^{(7)}$ & $\begin{array}{l}-0.593 \\
0.0001^{*}\end{array}$ & $\begin{array}{l}-0.81 \\
0.0001 *\end{array}$ & $\begin{array}{l}-0.145 \\
0.0001^{*}\end{array}$ & $\begin{array}{l}-0.208 \\
0.0001^{*}\end{array}$ & $\begin{array}{l}-0.207 \\
0.0001^{*}\end{array}$ & $\begin{array}{l}-0.467 \\
0.0001^{*}\end{array}$ & 1 \\
\hline
\end{tabular}

$r=$ Pearson correlation coefficient

* Statistically significant

$1=$ Knowledge of travel-associated diseases and malaria

$2=$ Travel health-related practices

$3=$ Perception of travel-associated risks

$4=$ Attitude toward vaccination

$5=$ Perceived threat of malaria

$6=$ Perceived benefits of malaria prophylaxis (drugs and measures)

$7=$ Perceived barriers to vaccination and malaria prophylaxis (drugs and measures)

and $92.8 \%$, respectively, of studied travelers identified malaria as a mosquito-borne disease, despite discrepancies between Egypt and developed countries as regards health knowledge and awareness.

Egyptian travelers had a low perception of the possibility and susceptibility of malaria infection and under-estimated the risks of malaria infection at their destinations compared to other studies done in Europe, ${ }^{20}$ Zimbabwe, ${ }^{26}$ South Africa, ${ }^{19}$ and Thailand, ${ }^{27}$ where the perception of risk of malaria infection was ultimately high. More than half of the interviewed travelers identified vaccination as a valid measure for protecting against malaria. In the United States, $11 \%$ of student travelers described receiving malaria vaccinations before traveling; almost half of the respondents in another study did not realize that there is no vaccine for malaria. ${ }^{24}$
Fever was known to $82.8 \%$ of Egyptian travelers, shivering was known to $36.5 \%$, and sweating was known to $34.2 \%$ as a main symptom of malaria. Fever has been identified as a major symptom of malaria by travelers worldwide, including Swiss (99\%), ${ }^{24}$ Spanish (83.5\%), ${ }^{16}$ Australian (71\%), ${ }^{17}$ Ethiopian (92.9\%), ${ }^{28}$ Chinese (68.9-71.8\%), ${ }^{23}$ American (89\%), ${ }^{18}$ and Thai $(70.4 \%)^{27}$ travelers.

Malaria chemoprophylaxis was perceived as unbeneficial (54.9\%) or of medium beneficence $(39.7 \%)$. This correlated with the practice of its use; $11.9 \%$ of travelers described malaria chemoprophylaxis as a preventive measure for malaria compared to $18.5 \%$ in China $^{23}$ and $70 \%$ in the Netherlands, ${ }^{29}$ while only $9.6 \%$ were carrying them. It is noteworthy that $88.3 \%$ of Egyptian travelers identified the main barrier to using these drugs as ignorance of their existence. 


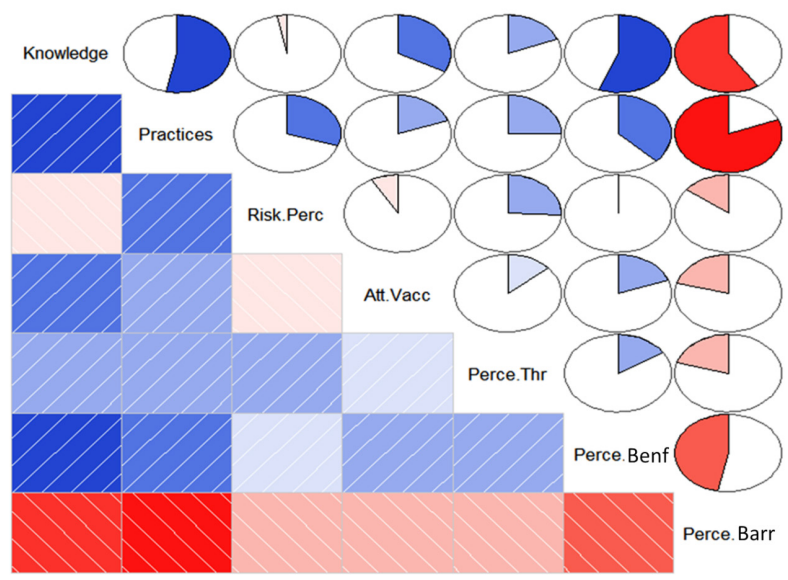

Figure 2. Correlation Matrix Between Percentage Scores of Different Elements of KAP. Blue color signifies positive correlation; Red color signifies negative correlation; The darker the color (more complete circle), the more significant the correlation.

Other barriers reported in other studies were forgetfulness, confusion about how to take them, and fear of side effects or ineffectiveness. ${ }^{16,25}$

Although the perception of general prophylactic measures against malaria could be considered good [medium beneficence $(47.1 \%)$ and very beneficial (14.3\%)], about $66.3 \%$ of travelers stated that they will not use any of them. The main barrier to using them was unfamiliarity with such measures (65.3\%). The barriers described in other studies included sleeping in air conditioning accommodations and forgetfulness. ${ }^{25,30}$

It is known that a part of the social norms and culture in Egypt is fatalism; that can explain why $37.1 \%$ and $53.2 \%$, respectively, stated that they trust in God as a main reason for neither receiving the drugs nor using other measures.

In the present survey, the knowledge level and eventually travel-associated practices improved with age. This should be alarming, as younger people are more vulnerable to travel hazards due to their risky behavior. This profile of poor knowledge among young people was also found in Australia, ${ }^{31}$ but in Oman, the knowledge level was excellent among those aged 18-34 years. ${ }^{32}$

Travel health knowledge and practices were better among travelers from urban residencies, which may be explained by more availability and easier access to information through different media outlets. The same was also found in Ethiopia, ${ }^{33}$ Cote d'Ivoire, ${ }^{34}$ and India. ${ }^{35}$

The knowledge and practices were better among those with higher levels of education, and more particularly, among those with a medical education. Travelers with health problems were more knowledgeable than others, as they gave more attention to health-seeking behavior and risk perception. Experienced travelers also had better knowledge than others. This makes sense and was consistent with reports by Zimmermann et al, ${ }^{36}$ and could be attributed to previous travel experience and exposure to previous travel hazards. In a study done in the KSA, it was evident that increasing age, increasing level of education, not traveling alone, and being in the Saudi Arabian eastern region were associated with higher knowledge scores. ${ }^{37}$
Travel health-related practices were significantly better among married participants who may adopt healthier practices to protect themselves and their accompanying families. Similarly, better economic status was associated with better practices, which may be attributed to a better educational level, more awareness about healthy behavior, or the absence of a financial barrier which may hinder healthseeking behavior.

The perceived barriers for vaccination and malaria prophylaxis were highest among younger age (less than 30 years), which could reflect inadequate knowledge, awareness, and experience among this age group. They were also higher among travelers from rural residencies, most probably due to deficient healthcare facilities in rural areas and general low health awareness. In Kuwait, ${ }^{38}$ the predictors of the barriers were nationality, followed by purpose of travel, duration of stay, and choice of travel destination. In Oman, being male, older than 60 years, and traveling for business were the significant predictors of perceived barriers. ${ }^{32}$

\section{Conclusion}

Although Egyptian travelers have unsatisfactory KAP towards almost every aspect of travel health, they have very promising indicators of much better results if they were given the appropriate services. Their knowledge and practice scores were improved among those with an older age, an urban residence, and a higher educational level. Despite the good attitude towards vaccination, the practice is poor. Lack of knowledge was the main barrier against sound practice.

\section{Authors' Contributions}

All authors contributed equally to this research.

\section{Conflict of Interest Disclosures}

None to declare.

\section{Ethical Approval}

The study strictly followed the ethical guidelines of the Helsinki Declaration and was approved by the High Institute of Public Health Ethics Committee. Participation of travelers 


\section{Research Highlights}

\section{What Is Already Known?}

There is a lack of the baseline data regarding Egyptian travelers pre-travel knowledge about malaria and their attitude towards malaria prophylaxis and vaccination practice.

\section{What This Study Adds?}

- Nearly $90 \%$ of Egyptian travelers knowledge had poor about the endemic diseases in the area they are travelling to.

- knowledge on malaria transmission was good in only $6.7 \%$ of them

- $66.3 \%$ of travelers didn't have acceptable practice of using malaria prophylactic.

- Despite a positive attitude towards vaccinations, $91.3 \%$ did not receive any vaccinations.

- Deficiency or lack of counselling were the leading cause without considering.

- Travel health practice in Egypt has to be improved.

was on a voluntary basis after written informed consent was obtained.

\section{Funding/Support}

None.

\section{References}

1. World Tourism Organization (UNWTO). Yearbook of tourism statistics data 2010-2014, compendium of tourism statistics and data files. Madrid: World Tourism Organization; 2014:906. doi:10.1016/S0924-8579(02)00293-5

2. Steffen R, deBernardis C, Banos A. Travel epidemiology--a global perspective. Int J Antimicrob Agents. 2003;21(2):89-95.

3. Lawson CJ, Dykewicz CA, Molinari NA, Lipman H, AlvaradoRamy F. Deaths in international travelers arriving in the United States, July 1, 2005 to June 30, 2008. J Travel Med. 2012;19(2):96103. doi:10.1111/j.1708-8305.2011.00586.x.

4. Schreiber W, Mathys FK. Infections diseases in the history of medicine. Basle, Switzerland: Editiones Roche; 1987:232.

5. Centers for Disease Control and Prevention (CDC). Measles cases and outbreaks. http://www.cdc.gov/measles/cases-outbreaks.html. Accessed Jan 2, 2016. Published 2015.

6. Halstead SB. Dengue. Lancet. 2007;370(9599):1644-1652. doi:10.1016/s0140-6736(07)61687-0.

7. Odolini S, Gautret P, Parola P. Epidemiology of imported malaria in the mediterranean region. Mediterr J Hematol Infect Dis. 2012;4(1):e2012031. doi:10.4084/mjhid.2012.031.

8. Sapa. "Malaria Hits SA Team after All Africa Games. IOL News. November 7, 2003. www.iol.co.za/news/south-africa/malariahits-sa-team-after-all-africa-games-116477. Accessed November 10, 2016.

9. Egyptian Ministry of Health and Population. MOHP Egypt website. https://www.elwatannews.com/news/details/1983558.

10. El Sherbiny NA, Wafik GM. A study of travel medicine among National and International travellers in Egypt. J Public Health Epidemiol. 2011;3(7):324-328.

11. El-Ghitany EM, Abdelmohsen MAM, Farghaly AG, Abd El-Gawwad E, Abd El-Wahab EW. Travel health survey: risk perception, healthseeking behavior, and subjective evaluation of travel health services in Egypt. Int J Travel Med Glob Health. 2018;6(1):16-24. doi:10.15171/ijtmgh.2018.04.

12. Zuckerman J. Shaping travel health and medicine for the future. Lancet Infect Dis. 2001;1(5):296-297. doi:10.1016/s14733099(01)00142-6.

13. Watanabe N, Kaneko A, Yamar S, et al. Determinants of the use of insecticide-treated bed nets on islands of pre- and post-malaria elimination: an application of the health belief model in Vanuatu. Malar J. 2014;13:441. doi:10.1186/1475-2875-13-441.

14. Altmann M, Parola P, Delmont J, Brouqui P, Gautret P. Knowledge, attitudes, and practices of French travelers from Marseille regarding rabies risk and prevention. J Travel Med. 2009;16(2):107-111. doi:10.1111/j.1708-8305.2008.00283.x.

15. Guerrero-Lillo L, Medrano-Diaz J, Perez C, Chacon R, Silva-Urra J, Rodriguez-Morales AJ. Knowledge, attitudes, and practices evaluation about travel medicine in international travelers and medical students in Chile. J Travel Med. 2009;16(1):60-63. doi:10.1111/j.1708-8305.2008.00263.x.

16. Lopez-Velez R, Bayas JM. Spanish travelers to high-risk areas in the tropics: airport survey of travel health knowledge, attitudes, and practices in vaccination and malaria prevention. J Travel Med. 2007;14(5):297-305. doi:10.1111/j.1708-8305.2007.00142.x.

17. Wilder-Smith A, Khairullah NS, Song JH, Chen CY, Torresi J. Travel health knowledge, attitudes and practices among Australasian travelers. J Travel Med. 2004;11(1):9-15. doi:10.2310/7060.2004.13600.

18. Hamer DH, Connor BA. Travel health knowledge, attitudes and practices among United States travelers. J Travel Med. 2004;11(1):23-26. doi:10.2310/7060.2004.13577.

19. Toovey S, Jamieson A, Holloway M. Travelers' knowledge, attitudes and practices on the prevention of infectious diseases: results from a study at Johannesburg International Airport. J Travel Med. 2004;11(1):16-22. doi:10.2310/7060.2004.13587.

20. Van Herck K, Van Damme P, Castelli F, et al. Knowledge, attitudes and practices in travel-related infectious diseases: the European airport survey. J Travel Med. 2004;11(1):3-8. doi:10.2310/7060.2004.13609.

21. Namikawa K, lida T, Ouchi K, Kimura M. Knowledge, attitudes, and practices of Japanese travelers on infectious disease risks and immunization uptake. J Travel Med. 2010;17(3):171-175. doi:10.1111/j.1708-8305.2010.00405.x.

22. Zhang $M$, Zhang J, Hao $Y$ et al. Vaccination knowledge, attitude and practice among Chinese travelers who visit travel clinics in Preparation for international travel. J Travel Med. 2016;23(6):taw051. doi:10.1093/jtm/taw051.

23. Zhang M, Liu Z, He H, et al. Knowledge, attitudes, and practices on malaria prevention among Chinese international travelers. J Travel Med. 2011;18(3):173-177. doi:10.1111/j.17088305.2011.00512.x.

24. Weber R, Schlagenhauf P, Amsler L, Steffen R. Knowledge, attitudes and practices of business travelers regarding malaria risk and prevention. J Travel Med. 2003;10(4):219-224. doi:10.2310/7060.2003.40574.

25. Teodosio R, Goncalves L, Atouguia J, Imperatori E. Quality assessment in a travel clinic: a study of travelers' knowledge about malaria. J Travel Med. 2006;13(5):288-293. doi:10.1111/j.17088305.2006.00060.x.

26. Laver SM, Wetzels J, Behrens RH. Knowledge of malaria, risk perception, and compliance with prophylaxis and personal and environmental preventive measures in travelers exiting Zimbabwe from Harare and Victoria Falls International airport. J Travel Med. 2001;8(6):298-303. doi:10.2310/7060.2001.23975.

27. Piyaphanee W, Wattanagoon Y, Silachamroon U, Mansanguan C, Wichianprasat P, Walker E. Knowledge, attitudes, and practices among foreign backpackers toward malaria risk in southeast Asia. J Travel Med. 2009;16(2):101-106. doi:10.1111/j.17088305.2008.00282.x.

28. Yimer F, Animut A, Erko B, Mamo H. Past five-year trend, current prevalence and household knowledge, attitude and practice of 
malaria in Abeshge, south-central Ethiopia. Malar J. 2015;14:230. doi:10.1186/s12936-015-0749-5.

29. van Genderen PJ, van Thiel PP, Mulder PG, Overbosch D. Trends in the knowledge, attitudes and practices of travel risk groups towards prevention of malaria: results from the Dutch Schiphol Airport Survey 2002 to 2009. Malar J. 2012;11:179. doi:10.1186/14752875-11-179.

30. Stoney RJ, Chen LH, Jentes ES, et al. Malaria Prevention Strategies: Adherence Among Boston Area Travelers Visiting Malaria-Endemic Countries. Am J Trop Med Hyg. 2016;94(1):136-142. doi:10.4269/ ajtmh.15-0565.

31. Heywood $A E$, Zhang $M$, Maclntyre $C R$, Seale $H$. Travel risk behaviours and uptake of pre-travel health preventions by university students in Australia. BMC Infect Dis. 2012;12:43. doi:10.1186/1471-2334-12-43.

32. Al-Abri SS, Abdel-Hady DM, Al-Abaidani IS. Knowledge, attitudes, and practices regarding travel health among Muscat International Airport travelers in Oman: Identifying the gaps and addressing the challenges. J Epidemiol Glob Health. 2016;6(2):6775. doi:10.1016/j.jegh.2016.02.003.

33. Abate A, Degarege A, Erko B. Community knowledge, attitude and practice about malaria in a low endemic setting of Shewa Robit Town, northeastern Ethiopia. BMC Public Health. 2013;13:312. doi:10.1186/1471-2458-13-312.

34. Ouattara AF, Raso G, Edi CV, et al. Malaria knowledge and longlasting insecticidal net use in rural communities of central Cote d'Ivoire. Malar J. 2011;10:288. doi:10.1186/1475-2875-10-288.

35. Tyagi P, Roy A, Malhotra MS. Knowledge, awareness and practices towards malaria in communities of rural, semi-rural and bordering areas of east Delhi (India). J Vector Borne Dis. 2005;42(1):30-35.

36. Zimmermann R, Hattendorf J, Blum J, Nuesch R, Hatz C. Risk perception of travelers to tropical and subtropical countries visiting a swiss travel health center. J Travel Med. 2013;20(1):3-10. doi:10.1111/j.1708-8305.2012.00671.x.

37. Alghamdi AH, Ibrahim AM, Al-Ghamdi MS, Ryan ET, Al-Raddadi R. Travel health in the Kingdom of Saudi Arabia: Perception and practice of Saudi travelers. Int J Health Res Innov. 2014;2(2):25-39.

38. Shady I, Gaafer M, Bassiony L. Travel risk behaviors as a determinants of receiving pre-travel health consultation and prevention. Trop Dis Travel Med Vaccines. 2015;1:3. doi:10.1186/ s40794-015-0003-8. 